\section{Global supplier acquires cloud-based dental software provider}

Software of Excellence, a wholly owned subsidiary of Henry Schein One, has announced its acquisition of cloud-based UK dental software provider, Dentally, owned by NJ Technologies. Henry Schein One is a joint venture between Henry Schein, Inc. and Internet Brands that deliver integrated technology to enhance dental practice management.

Software of Excellence is a global supplier of dental practice management software. It has become established as one of the most forward thinking and innovative voices in the sector, providing dental software and technologybased business solutions for dental practitioners in the UK and abroad.

Dentally was founded in 2011 by Nick Davies, Chief Executive Officer, and James Harker, Chief Technology Officer, and has since grown to become an innovative provider for UK dentists searching for a flexible, cloud-based practice management solution. Under the terms of the acquisition, Mr Davies and Mr Harker will remain with the company, as the whole Dentally team joins Software of Excellence's current, 150-strong workforce based in Gillingham.

Dentally had sales for the 12 months ended 31 May 2020 of approximately $£ 1.5$ million. Henry Schein, Inc. expects that Dentally will be neutral to the Company's 2020 earnings per diluted share and accretive thereafter. Financial terms were not disclosed.

\title{
Treat a broader range of patient cases
}

Align Technology, Inc. has launched the latest addition to the Invisalign Go system, available to general practitioners in the EMEA region. The new Invisalign Go Plus system further extends the Invisalign Go system, enabling general dentists to treat a broader range of patient cases.

The Invisalign Go Plus system is designed specifically for general dentists. It enables doctors to treat mild to moderate types of malocclusions. The Invisalign Go Plus system can easily be integrated in a wide range of restorative treatments in a dental practice. It offers a 26-stage treatment option to correct anterior teeth up to, and including, the first molar, over a period of six to 12 months, for an improved arch formation.

The Invisalign system is the world's most advanced clear aligner system, which uses best-in-class SMART technology, developed by Align Technology. All clear aligners are not alike, and only Invisalign aligners are made from SmartTrack material and include SmartForce features, which allow for more predictable tooth movement.

The combination of SmartTrack material and SmartForce features are clinically proven to improve control of tooth movement, allowing a greater than $75 \%$ improvement in tooth movement predictability. This is unmatched by any other clear aligner system made from offthe-shelf single layer material and enables exceptional, predictable results.

For more information about Invisalign Go Plus system, visit https://www. invisalign-go.co.uk/.

\section{A solid start to dental implantology}

For anyone considering a new venture for the next chapter of their dental career, the PG Cert in Implant Dentistry will provide a solid foundation to get started in the field.

Delivered through Ucer Education and led by Specialist Oral Surgeon, Professor Cemal Ucer, the 12-month modular course combines both theoretic and practical training for a

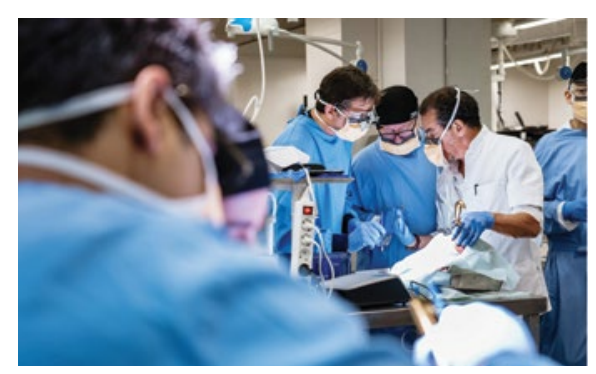

comprehensive learning experience, followed by clinical training under supervision at the centre. A highly experienced training faculty cover a wide range of relevant topics, enabling delegates to work towards their EduQual Level 7 qualification.

Complemented by the exceptional facilities at the Centre of Oral-Maxillofacial and Dental Implant Reconstruction in Manchester and the ICE Postgraduate Hospital, the next cohort starts in November. Find out more or register for your place today!

For more information on the PG Cert in Implant Dentistry from Ucer Education supported by Geistlich, Megagen, Neoss, TRI Implants and General Medical - visit www.ucer education or contact Prof Ucer at ice@ucer.uk.

\section{Ditch the tube and chew your toothpaste}

1.5 billion toothpaste tubes are put into landfill every year. Tongue's Chewable Toothpaste Tablets allow patients to 'ditch the tube' and take care of the environment.

Made by dentists in the UK, Tongue's Chewable Toothpaste Tablets are a replacement for toothpaste, with the perfect sized tablet to provide the correct amount of toothpaste for every brush. The tablets are also naturally whitening and provide the correct amount of fluoride. They are far more convenient than toothpaste powders and are perfect to travel with - simply take as many tablets as you need. Contained in one re-sealable and biodegradable bag is 180 tablets, or a threemonth supply. The tablets are a cool and refreshing peppermint flavour and aimed at everyone over the age of seven, and they are also organic, SLS free and vegan friendly.

You can also purchase a jar separately for Toothpaste Tablet storage, and a threemonthly repeat subscription is available.

For more information visit www.tongues. club.

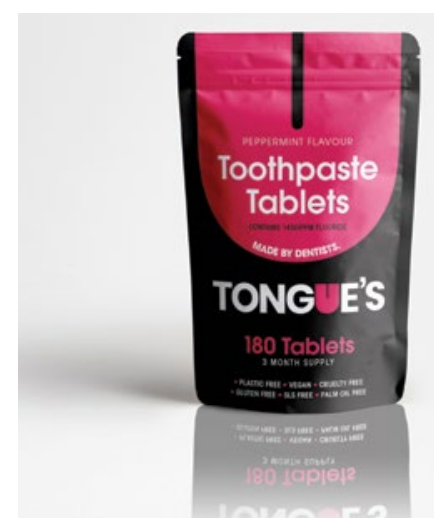

